\title{
Expert system for modelling stopover site selection by barnacle geese
}

\author{
Mitra Shariati $^{\mathrm{a}, *}$, Andrew K. Skidmore ${ }^{a}$, Roshanak Darvishzadeh ${ }^{\mathrm{a}}$, Klaus-Michael Exo ${ }^{\mathrm{b}}$, \\ Andrea Kölzsch ${ }^{\mathrm{c}, \mathrm{d}}$, Larry Griffin ${ }^{\mathrm{e}}$, Julia Stahl ${ }^{\mathrm{f}}$, David Cabot ${ }^{\mathrm{g}}$, Albertus G. Toxopeus ${ }^{\mathrm{a}}$ \\ a Faculty of Geo-Information Science and Earth Observation (ITC), University of Twente, Enschede, The Netherlands \\ ${ }^{\mathrm{b}}$ Institute of Avian Research, Wilhelmshaven, Germany \\ ${ }^{c}$ Max Plank Institute for Ornithology, Department of Migration and Immuno-Ecology, Vogelwarte, Radolfzell, Germany \\ ${ }^{\mathrm{d}}$ Department of Animal Ecology and Project group Movement Ecology, Netherlands Institute of Ecology (NIOO-KNAW), Wageningen, The Netherlands \\ e Wildfowl \& Wetlands Trust, Slimbridge, Gloucestershire, UK \\ ${ }^{\mathrm{f}}$ Sovon Dutch Centre for Field Ornithology, Nijmegen, The Netherlands \\ ${ }^{g}$ Environmental Consultancy Services, Carrigskeewaun, Carrowniskey, Westport, Co. Mayo, Ireland
}

Keywords:

Foraging habitat

GPS locations

Human disturbance

Roosting areas

Site safety

\begin{abstract}
A B S T R A C T
The study of stopover sites has received a lot of attention in avian ecology, being especially important for many long-distance migrants, some of which have to pause several times during migration. The survival of many migratory birds depends primarily on food availability at these stopovers. However, previous studies show that there is a lack of knowledge about site selection where migratory birds stop to refuel energy stores. In the present study, a Bayesian expert system has been used to incorporate environmental parameters, to determine their relationship with the presence of barnacle geese at stopover sites. Data on stopover sites was obtained from satellite-tracked barnacle geese (Branta leucopsis) for three different breeding populations in the Western Palearctic (i.e. Russian, Svalbard and Greenland). The results from the present study showed that the posterior probability of presence at the stopover sites obtained from the Bayesian model was close to one. Therefore, the Bayesian expert system detected the stopover sites of the geese correctly and can be used as a proper method for modelling the presence of barnacle geese at the stopover sites in the future. This study introduces a new method into movement ecology to identify and predict the importance of different environmental parameters for stopover site selection by migratory geese. This is particularly important from both a conservation and an agro-economic point of view with the goal of reducing possible conflicts between geese and agricultural interests.
\end{abstract}

\section{Introduction}

Stopovers are places along a migration route where birds mostly rest and forage to replenish energy reserves before continuing their journeys (Newton, 2008). Having such breaks during migration is especially important for Arctic-nesting geese as many of them are partial capital breeders and may bring body stores to the breeding grounds, in order to survive initial adverse conditions and produce a clutch of eggs soon after arrival (Gauthier et al., 2003). However, there is a lack of knowledge about the selection of these sites, where birds choose to stop and forage (Newton, 2008).

\footnotetext{
* Corresponding author at: PO Box 217 7500, AE Enschede, The Netherlands. E-mail addresses: mitra.sh.na@gmail.com (M. Shariati), a.k.skidmore@utwente.nl (A.K. Skidmore),r.darvish@utwente.nl (R. Darvishzadeh), michael.exo@ifv-vogelwarte.de (K.-M. Exo), akoelzsch@orn.mpg.de (A. Kölzsch), Larry.Griffin@wwt.org.uk (L. Griffin), Julia.Stahl@sovon.nl (J. Stahl), david@cabotandco.com (D. Cabot), a.g.toxopeus@utwente.nl (A.G. Toxopeus).
}

Habitat selection is greatly influenced by a variety of environmental parameters, which includes food availability and the costs related to predation or disturbance risks, e.g. from farmers, as well as inter- and intra-specific competition (Chudzińska et al., 2015). Since, herbivore species follow peaks in the availability of highquality forage, it is presumed that variation in this resource drives annual migration (Owen, 1980; Shariatinajafabadi et al., 2014; van der Graaf et al., 2006). Sites selected by the geese were generally located in a lowland region and far from woodland edges, possibly to minimize predation risk (Jankowiak et al., 2008; Roder et al., 2008; Rosin et al., 2012). Moreover, geese prefer large fields that are remote from human settlements (Rosin et al., 2012). The negative impact of human settlements on foraging sites has been attributed by farmers, domestic dogs, foxes, traffic volumes and windfarms (for more information see Jensen et al., 2008; Keller, 1991; Langston, 2013; Rosin et al., 2012)

Lakes and coastal waters are usually used by geese as roosting and daily resting sites during migration (Rosin et al., 2012). 
Distance to open water (i.e. sea or lakes) is related to energy expenditure as geese must use additional energy to move from a roosting site to a distant foraging site. It is also shown in studies that goose occurrence declined significantly with the increase in distance from feeding sites to open water (Jensen et al., 2008). Therefore, geese primarily use fields that are closer to roosting sites (e.g. Jensen et al., 2008).

It is seen that effective conservation and management of migratory birds, requires species distributional data to determine the distribution of stopovers and the pathways used between them (Faaborg et al., 2010). It is recommended that specific attention should be given to stopover sites, as the functional role of a given stopover site in meeting the needs of migrants is highly dynamic with respect to resource availability, landscape context, the physiological condition of the migrants and mortality risks (Mehlman et al., 2005). Moreover, recent technological advances, such as satellite tracking, allow to track birds throughout the annual cycle, determine their migratory routes and map the often remote stopovers with great accuracy (Klaassen et al., 2014; Pedrana et al., 2015). For instance, the migration routes and location of stopover sites of bar-headed geese (Anser indicus) in China (Guo-Gang et al., 2011) and Svalbard barnacle geese (Griffin, 2008) has been determined with the use of satellite tracking.

Moreover, species distribution modelling (SDM) has been widely applied to quantify the relationship between species distribution and environmental parameters and to predict species' occurrence across un-sampled areas (Guisan and Thuiller, 2005; Miller, 2010). Currently, a variety of statistical models are being used for modelling species distributions (see review by Guisan and Thuiller, 2005). However, an intensive field survey for generating in-situ data is costly in terms of time and resources (James et al., 2001). In such cases, expert knowledge can be a less expensive source of information where there is insufficient field data for remote breeding and wintering areas (Murray et al., 2009). In addition, Bayesian statistics provide a mechanism to incorporate such knowledge into species distribution models (Choy et al., 2009). With the use of a priori probability of occurrence (prior knowledge), conditional to the value of each environmental parameter (likelihood function) which is obtained based on experts' rules, the Bayesian expert system can be formulated (Skidmore, 1989).

Bayesian method has been argued to be advantageous over frequentist statistics and its use in ecological studies has been encouraged (Ellison, 1996). For instance, the Bayesian method has the ability to incorporate various kinds of uncertainty into the analysis (e.g. uncertainty of the estimate) even for unknown parameters (Taylor et al., 1996). Moreover, the results that are presented in Bayesian frameworks can be understood more easily by decisionmakers. Also, additional environmental parameters can be quickly incorporated into a Bayesian expert system as data layers and the posterior probability can be kept updated (Skidmore, 1989; Wade, 2000). However, despite the beneficial aspects of using the Bayesian method, it has been used relatively rare in ecological studies (McCarthy, 2007).

The Bayesian approach can also be applied in habitat distribution modelling (Guisan and Zimmermann, 2000; Niamir et al., 2011). Aspinall (1992) applied a GIS-based Bayesian modelling method for predicting the spatial distribution of red deer (Cervus elaphus) in Scotland. Moreover, Kynn (2005) also incorporated expert knowledge as prior knowledge, to a Bayesian logistic regression for modelling species habitat distribution. Nevertheless, as far as we know, this method has never been used to model stopover selection of migratory birds.

The present study investigates stopover behaviour of 37 satellite-tracked barnacle geese from three different populations in the Western Palearctic, transiting between temperate and high Arctic latitudes. Considering the practical advantages of Bayesian statistics, such as taking uncertainty into account and simplicity in explaining the results (Wade, 2000) we were interested to assess, whether a Bayesian expert system can appropriately model stopover site selection of barnacle geese during spring migration, by utilizing the detailed knowledge of goose ecologists.

\section{Material and method}

\subsection{Satellite tracking data and stopover sites}

Barnacle geese from three long-distance migratory populations in the Western Palearctic (Russia, Svalbard and Greenland) were captured at their overwintering sites and equipped with solar GPS/ARGOS transmitters attached to the back of the birds, using a nylon elasticated harness. The transmitters used in this study were $30 \mathrm{~g}$ Solar GPS 100 PTT (PTT-platform transmitter terminal; Microwave Telemetry, Inc., Columbia, MD, USA) for the Russian birds and a mix of $30 \mathrm{~g}$ and $45 \mathrm{~g}$ PTTs for the Svalbard and Greenland birds (Table 1 ). In total 30 full data tracks for 12 individuals of the Russian population (2008-2011), 20 full data tracks for 18 individuals of the Svalbard population (2006-2011) and 7 full data tracks for 7 individuals of the Greenland population (2008-2010) were collected during spring migration (Table 1). The barnacle goose tracking data has been stored in Movebank (https://www.movebank.org: Russian population: "Migration timing in barnacle geese (Barents Sea), data from Kölzsch et al., 2015 and Shariatinajafabadi et al., 2014", DOI: 10.5441/001/1.ps244r11 (ii) Svalbard population: "Migration timing in barnacle geese (Svalbard), data from Kölzsch et al., 2015 and Shariatinajafabadi et al., 2014", DOI: 10.5441/001/1.5k6b1364 (iii) Greenland population: "Migration timing in barnacle geese (Greenland), data from Kölzsch et al., 2015 and Shariatinajafabadi et al., 2014", DOI: 10.5441/001/ $1.5 \mathrm{~d} 3 \mathrm{f0} 664$.

For each GPS track, stopover sites were defined as an area where the geese would remain within a radius of $30 \mathrm{~km}$ for at least $48 \mathrm{~h}$ (for more information see Shariati-Najafabadi et al., 2015). In total, 64 stopover sites were identified along the Russian flyway (2008-2011), 32 along the Svalbard flyway (2006-2011), and 14 along the Greenland flyway (2008-2010) for 12, 18 and 7 geese, respectively, during the spring migration (see Table 1 and Fig. 1). Also, from the Russian and Svalbard barnacle geese that were tracked for more than 1 year, only two from year to year. Nevertheless, none of them arrived at these stopover sites on the same date as in other years.

\subsection{Environmental parameters}

A set of environmental parameters known to be important in determining stopover selection of barnacle geese have been reviewed (Amano et al., 2006; Jensen et al., 2008; Rosin et al., 2012; Si et al., 2011). The selected parameters have been categorized into four groups based on Rosin et al. (2012): human disturbance (1), site safety (2), distance from the roosting area (3) and the foraging habitat (4) (Table 2). Distance to roads, cities, towns and wind farms were used as indicators of human disturbance, distance to the forest as an indicator of site safety from predators, and distance to river, inland water and ocean as the proximity to roosting areas. The maps of roads, cities, town, rivers, ocean area and inland waters were derived from ESRI (2016), and the wind farm data was obtained from The wind power (2016).

Also, in the present study, factors like the site elevation, greenness factor, percentage of grassland/cropland, percentage of salt marsh and snow cover, at each stopover site were used to describe foraging habitat. Study involved extracting site elevation from a digital elevation model (DEM) generated by Global 
Table 1

Bird ID, tracking year for spring migration and the number of stopover sites for 12 Russian barnacle geese from 2008 to 2011,18 Svalbard barnacle geese from 2006 to 2011 and 7 Greenland barnacle geese from 2008 to 2010.

\begin{tabular}{|c|c|c|c|c|c|c|c|c|}
\hline \multicolumn{3}{|c|}{ Russian population $(\mathrm{n}=12)$} & \multicolumn{3}{|c|}{ Svalbard population $(\mathrm{n}=18)$} & \multicolumn{3}{|c|}{ Greenland population $(\mathrm{n}=7)$} \\
\hline Bird ID & Track year & $\begin{array}{l}\text { No. of stopover } \\
\text { sites }(\text { sum }=64)\end{array}$ & Bird ID & Track year & $\begin{array}{l}\text { No. of stopover } \\
\text { sites }(\text { sum }=32 \text { ) }\end{array}$ & Bird ID & Track year & $\begin{array}{l}\text { No. of stopover } \\
\text { sites }(\text { sum }=14 \text { ) }\end{array}$ \\
\hline 78033 & 2009-2011 & 3 & 33103 & 2011 & 1 & 65698 & 2009 & 2 \\
\hline 78034 & 2009-2011 & 4 & 33953 & 2010 & 2 & 70563 & 2010 & 2 \\
\hline 78035 & 2009-2011 & 3 & 33954 & 2010 & 1 & 78199 & 2010 & 2 \\
\hline 78036 & 2009-2010 & 3 & 64685 & 2006 & 1 & 78207 & 2008 & 2 \\
\hline 78037 & 2009 & 2 & 64687 & 2006-2007 & 2 & 78208 & 2008 & 2 \\
\hline 78039 & 2009-2011 & 7 & 70564 & 2007 & 1 & 78209 & 2008 & 1 \\
\hline 78041 & $2008-2010$ & 6 & 70565 & 2007 & 1 & 78210 & 2008 & 3 \\
\hline 78043 & $2008-2010$ & 10 & 70566 & 2007 & 1 & & & \\
\hline 78044 & $2008-2010$ & 10 & 70567 & 2007 & 1 & & & \\
\hline 78045 & 2008 & 4 & 70618 & 2007 & 1 & & & \\
\hline 78046 & 2008-2009 & 2 & 70619 & 2007 & 2 & & & \\
\hline \multirow[t]{7}{*}{78047} & $2008-2010$ & 10 & 78198 & 2008 & 5 & & & \\
\hline & & & 78378 & 2008-2009 & 3 & & & \\
\hline & & & 86824 & 2009 & 1 & & & \\
\hline & & & 86828 & 2009 & 1 & & & \\
\hline & & & 170563 & 2007 & 3 & & & \\
\hline & & & 178199 & 2008 & 3 & & & \\
\hline & & & 186827 & 2009 & 2 & & & \\
\hline
\end{tabular}

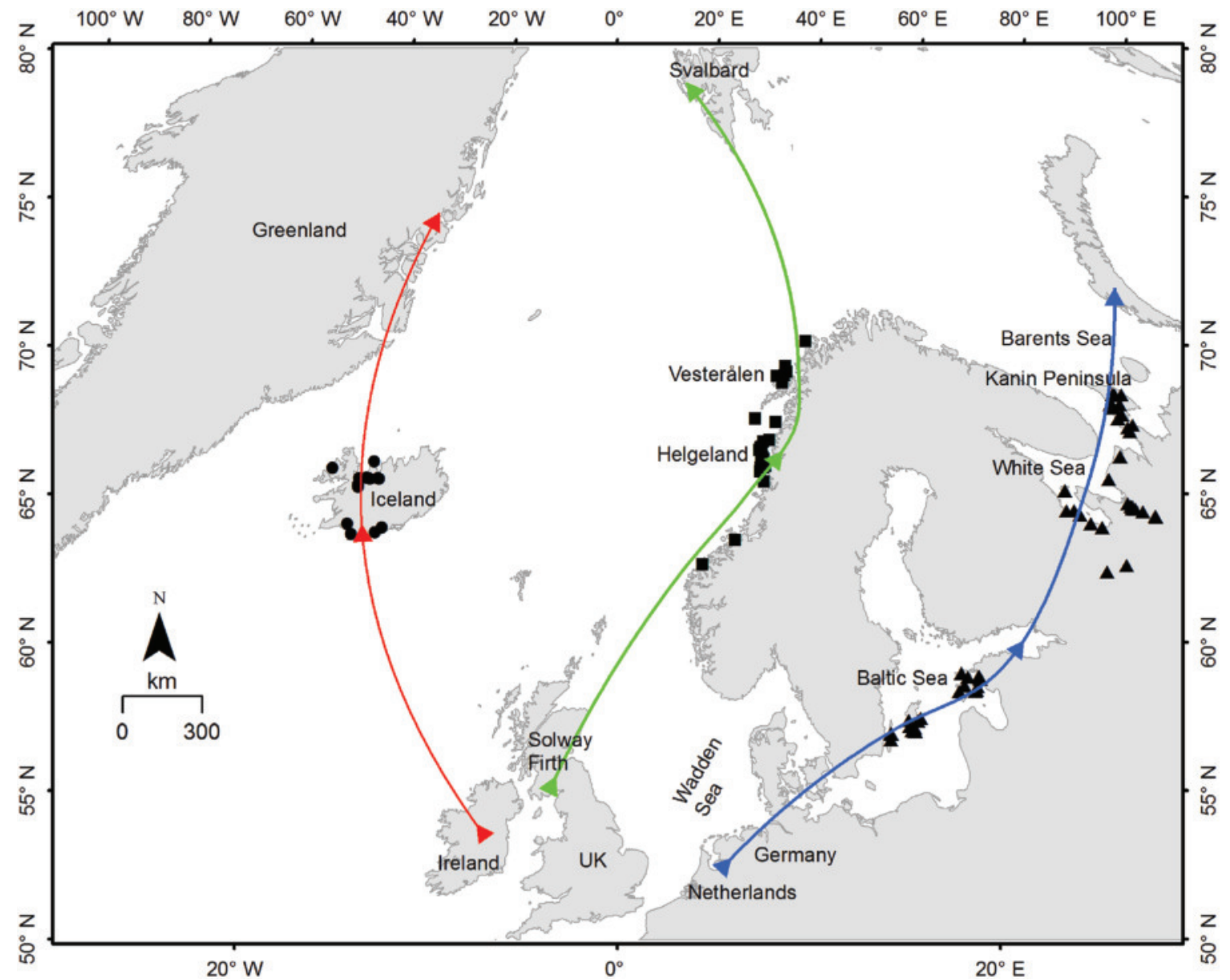

Fig. 1. The blue, green and red arrows show spring migration routes from wintering to breeding sites for the Russian, Svalbard and Greenland barnacle goose populations, respectively. The black triangles, squares, and circles denote the stopover sites for 12 Russian geese from 2008 to 2011, 18 Svalbard geese from 2006 to 2011 and 7 Greenland geese from 2008 to 2010, respectively. (For interpretation of the references to colour in this figure legend, the reader is referred to the web version of this article.)

Multi-resolution Terrain Elevation Data 2010 (GMTED2010) at 7.5 -arc-second $(225 \mathrm{~m})$ resolution. The greenness factor, which is referred to as the satellite-derived 'green wave index' (GWI) (Shariatinajafabadi et al., 2014) was calculated from the MODIS 16-day composite NDVI dataset (MOD13A2) with a $1 \mathrm{~km}$ spatial resolution for the period from 2006 to 2011 (Beck et al., 2008; Huete et al., 2002; Shariati-Najafabadi et al., 2015). In addition, the study analysis included extracting the land cover types (i.e. forest, grassland/cropland and salt marsh) from Envisat's Medium Resolution Imaging Spectrometer (http://www.esa.int) and measuring 
Table 2

Environmental parameters $(n=14)$ used to model the stopover selection of barnacle geese.

\begin{tabular}{ll}
\hline Category & Parameter \\
\hline 1)Human disturbance & Distance-to-cities $(\mathrm{km})(>50,000$ citizens $)$ \\
& Distance-to-town $(\mathrm{km})(<50,000$ citizens $)$ \\
& Distance-to-local road $(\mathrm{km})$ \\
& Distance-to-major roads incl. highways $(\mathrm{km})$ \\
& Distance-to-wind farms $(\mathrm{km})$ \\
2)Site safety & Distance-to-forest $(\mathrm{km})$ \\
3)Roosting areas & Distance-to-inland water/lake $(\mathrm{km})$ \\
& Distance-to-ocean $(\mathrm{km})$ \\
4)Foraging habitat & Distance-to-river $(\mathrm{km})$ \\
& Elevation $(\mathrm{m})$ \\
& Greenness factor $(\mathrm{GWI})$ \\
& Percentage cover of grassland/cropland \\
& Percentage cover of salt marsh \\
& Percentage cover of snow \\
\hline
\end{tabular}

the percentage of each land cover at each stopover site. The percentage of snow cover (April-Jun) was obtained from MODIS/Terra Snow Cover Daily L3 Global for each $0.05^{\circ}$ grid cell (c. $5 \mathrm{~km}$ by $5 \mathrm{~km}$ ). Raster data were converted to vector, and the parameters have been extracted from a $15 \mathrm{~km}$ radius around each stopover site, which is the distance of the foraging site for barnacle geese (Pendlebury et al., 2011). The analyses were performed using ArcGIS ver. 10.3.1 and ENVI-IDL ver. 5.3.

\subsection{Bayesian expert system}

The researchers of the current study are aware of the nonindependent quality of the study's data set (pseudo-replication). However, this can be a problem with frequentist statistical methods and not with Bayesian. For frequentist procedures, the underpinning assumption is that data is random and parameters are fixed, while it is vice versa under a Bayesian approach (Dobson and Barnett, 2008). It was discussed by Ellison (1996) that assuming a fixed value of the parameter of interest obtained from random sampling is not logical from an ecological perspective. This is partly because of pseudo-replication in the design and analysis of ecological field experiments (Hurlbert, 1984). While using Bayesian statistics, the study did not face this problem because data is fixed and once created cannot be recreated (Dobson and Barnett, 2008).

In the present study, a forward chaining expert system, which is a data-driven approach, has been used to infer the posterior probability of presence of barnacle geese at a location of stopover site based on the predictors and expert knowledge (Niamir et al., 2011; Skidmore, 1989). With the use of forward chaining strategy, the expert system is able to reach a solution via a sequential evaluation of all hypotheses or evidence (Naylor, 1989).

Our hypothesis implies that the site $\left(X_{i j}\right)$ is selected by barnacle geese $(H)$. Bayes' theorem is used to predict the probability $(H)$ that barnacle goose stopover selection occurs at a site $\left(X_{i j}\right)$, given an environmental explanatory variable:

$P\left(H \mid E_{b}\right)=\frac{P\left(E_{b} \mid H\right) \times P(H)}{P\left(E_{b}\right)}$

where $P\left(H \mid E_{b}\right)$ is the posterior probability of presence. $P\left(E_{b} \mid H\right)$ is the conditional probability that a piece of evidence $\left(E_{b}\right)$ (a specific environmental condition) occurs given that the site $X_{i j}$ has been selected as a stopover site. These are estimated according to expert knowledge and listed in Table A1. $P(H)$ is the probability for the hypothesis $(H)$ that a concrete site is selected (the prior). $P(H)$ was initially set to one. On iterating with further pieces of evidence (environmental parameters), $P\left(H \mid E_{b}\right): b=1$ replaces $P(H)$ in Eq. (1).
Table 3

The mean of the posterior probabilities for presence at the stopover sites for three populations of barnacle geese (by removing one parameter at a time from the Bayesian model). The $\mu P\left(H \mid E_{b}\right)>0.5$ are in bold type.

\begin{tabular}{llll}
\hline Removed parameter & $\begin{array}{l}\text { Russian pop. } \\
\mu P\left(H \mid E_{b}\right)\end{array}$ & $\begin{array}{l}\text { Svalbard pop. } \\
\mu P\left(H \mid E_{b}\right)\end{array}$ & $\begin{array}{l}\text { Greenland pop. } \\
\mu P\left(H \mid E_{b}\right)\end{array}$ \\
\hline Pop >50000 & 0.2543 & 0.2091 & 0.3400 \\
Pop <50000 & 0.2543 & 0.2091 & 0.3400 \\
Local road & 0.2543 & 0.2091 & 0.3400 \\
Major road & 0.2543 & 0.2091 & 0.3400 \\
Wind farm & 0.2567 & 0.1925 & 0.3238 \\
Forest & 0.2548 & 0.2091 & 0.3404 \\
Inland water & 0.2538 & 0.2093 & 0.3388 \\
Ocean & 0.2547 & 0.2086 & 0.3402 \\
River & 0.2549 & 0.2092 & 0.3405 \\
Elevation & 0.2535 & 0.2084 & 0.3374 \\
GWI & 0.2530 & 0.2089 & 0.3399 \\
Grass/crop & 0.2588 & 0.2100 & 0.3369 \\
Salt marsh & $\mathbf{0 . 8 3 0 7}$ & $\mathbf{0 . 9 1 1 0}$ & $\mathbf{0 . 9 0 3 8}$ \\
Snow cover & 0.2362 & 0.1818 & 0.3089 \\
\hline
\end{tabular}

$\mu P\left(H \mid E_{b}\right)$ : mean of posterior probability of presence.

$P\left(E_{b}\right)$ is the probability of the evidence alone, and was calculated from the following equation:

$P\left(E_{b}\right)=\sum_{i=1}^{n} P=\left(E_{b} \mid H_{i}\right) * P\left(H_{i}\right)$

To put it more clearly in the terms used in this manuscript:

$P\left(E_{b}\right)=P\left(E_{b} \mid H\right) * P(H)+P\left(E_{b} \mid-H\right) * P(-H)$

where $H$ is the hypothesis that a site is selected by the geese and $-H$ is the hypothesis that the site is not selected. In other words, it is not a summation across the pieces of evidences for the same hypothesis, but it is a summation across the hypotheses for the same piece of evidence.

\subsection{Model assessment}

During the study analysis, the posterior probability of presence at each stopover site has been calculated. The most likely hypothesis for each stopover site is the hypothesis with the maximum posterior probability (Skidmore, 1989). A zero (0) probability means that there is no chance of presence at stopovers, while a probability of one (1) means that it is highly likely to occur. The value 0.5 is the central point and the probabilities above it are more likely to occur, whereas the probabilities lower than 0.5 are less likely to occur (O'Hagan et al., 2006). Therefore, the Bayesian expert system has modelled the stopover selection correctly if the posterior probability of presence at stopover sites is higher than 0.5 .

\section{Results}

When all parameters were included in the model, the mean of the posterior probabilities for presence $\mu P\left(H \mid E_{b}\right)$ at the stopover sites was below 0.5 for all three populations (Russian: $\mu P\left(H \mid E_{b}\right)=$ 0.25 ; Svalbard: $\mu P\left(H \mid E_{b}\right)=0.21$; Greenland: $\mu P\left(H \mid E_{b}\right)=0.34$; Table 3$)$. Next, the study repeated the analysis by removing one parameter at a time from the Bayesian model and then evaluated the posterior probability of presence. The results showed that the posterior probability of presence was close to one when salt marsh was removed from the Bayesian model (Table 3).

\section{Discussion}

The Bayesian expert system correctly identified the presence of barnacle geese at stopover sites using environmental parameters 
A

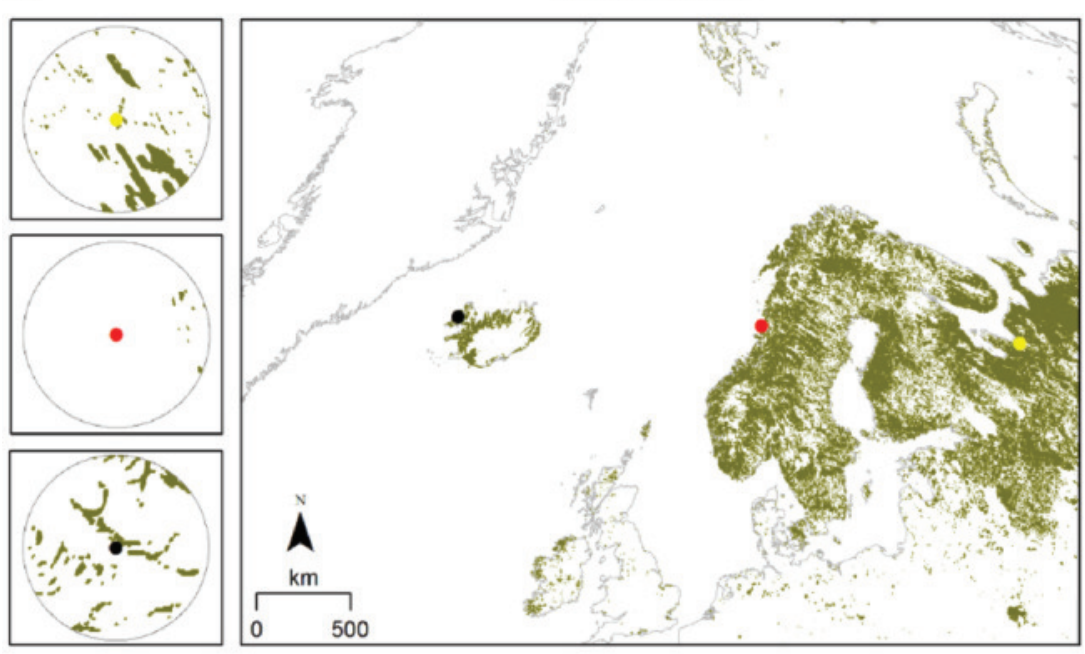

B
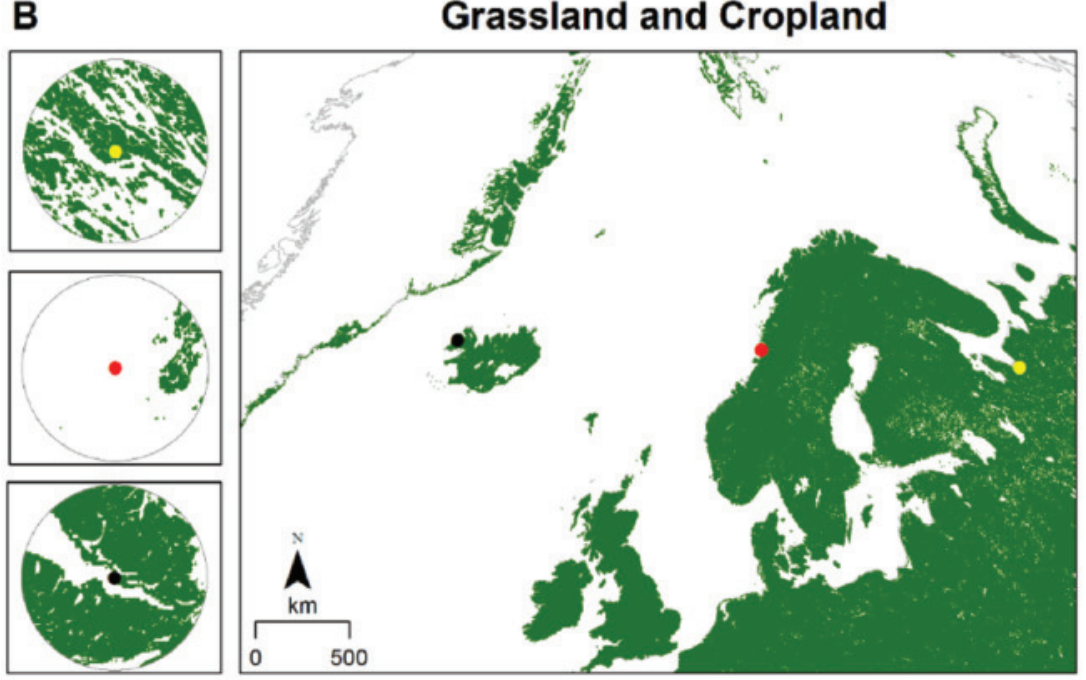

Fig. 2. A representative example showing the difference between the coverage area by the salt marsh (A) and grassland/cropland (B) land covers in the study area. The left-hand column shows the difference between the coverage area by salt marsh (A) and grassland/cropland (B) land covers at the three sampled stopover sites belonging to individuals' ID 78033 (year 2009) from the Russian population (yellow circle), 86824 (year 2009) from the Svalbard population (red circle) and 78209 (year 2008 ) from the Greenland population (black circle). (For interpretation of the references to colour in this figure legend, the reader is referred to the web version of this article.)

and expert knowledge. The resultant posterior probability of barnacle goose presence was rather low when all 14 parameters were included in the model (see Table 3). However, excluding the salt marsh from the model increased the probability of presence - in other words saltmarsh is not strongly linked with the presence of migrating geese. With reference to the conditional probabilities generated by the current study's avian experts (Table A1), it is most likely that barnacle geese choose sites with more than $50 \%$ salt marsh and grassland/cropland coverage. Therefore, our study reveals a close match between experts' opinion and the reality for the grassland/cropland land cover since on average $60 \%$ of the stopovers' areas were covered by the grassland/cropland. However saltmarsh covered only $10 \%$ of the stopover areas. As presented in Fig. 2, salt marsh covered much smaller parts of the study area and stopover sites compare to grassland/cropland. It is known that salt marsh is an important foraging habitat for barnacle geese (Prins and Ydenberg, 1985; van der Graaf et al., 2004). Instead, our findings may indicate that experts are under-estimating the importance of small areas of salt marsh. Thus, a smaller area of salt marsh within a mosaic of other land covers at stopover sites may provide important habitat for barnacle geese. More specifically, the individual geese are may be utilizing small linear fringes of marsh surrounding an island, for example. This results hint at two potential disadvantages for the expert system: firstly that an expert may have a poor ability extrapolating beyond their region of knowledge (Murray et al., 2009), and secondly that the questions used to elicit responses from experts may not be explicit and obvious to an expert given the context of extrapolating beyond their region of knowledge.

The probability of presence at a site is rarely calculated by ecologists because the statistical methods used by most ecologists are not well-suited to this objective (McCarthy, 2007). Frequentist statistical methods are not strictly suitable for predicting whether a species is present or absent because they are strictly limited to assessing long-run averages, rather than predicting individual observations (Quinn and Keough, 2002). However, as discussed by McCarthy (2007), the Bayesian approach provides a satisfactory answer to this question. The advantage with Bayesian statistics is that it can incorporate prior information and update the probability once evidence is available (i.e. the probability that the null hypothesis is true). The importance of prior knowledge can be understood 
with reference to an example provided by McCarthy (2007): if a researcher visits a habitat that appears to be an excellent habitat for frogs, then a failure to detect them on a single visit would not necessarily make the researcher believe that the frog was absent. However, if the researcher visited a habitat that was very unlikely to be a proper location for this species, even a single failure to detect the frog might be enough to convince the researchers of their assumption that this is not an appropriate habitat for frogs. The current study focussed on the probability that barnacle geese present at the stopover sites, which can be answered by Bayesian analysis (Dobson and Barnett, 2008; McCarthy, 2007).

The informative prior probabilities were used to model the presence of geese at stopovers in this current study using a forward chaining Bayesian expert system. Alternatively, the model can be started with no information (objective or non-informative prior), and the posterior derived from the first experiment can then be used as the prior for the next one (Ellison, 2004). However, it is a possibility that the potential stopover sites, which are predicted by the model will never be used by the geese. This is because, beside environmental parameters, there are other factors, such as population growth, which may affect stopover selection. For instance, it has been observed that barnacle geese skipped stopover sites in the Baltic Sea area, as a response to a population explosion and increased competition for food, which in turn has caused the energy deposition rate to fall below the limit of usefulness in time-selected migration (Eichhorn et al., 2009).

Nowadays, geese are highly dependent on agricultural food resources, and due to increasing population sizes, there are often conflicts with farmers in different European countries (Cope et al., 2003; Jensen et al., 2008). Solving of such conflict needs regional and even internationally coordinated management plans and the latter depends on the correct identification of stopover sites (Jensen et al., 2008; Madsen et al., 2014). Moreover, the study reveals that there is a lack of knowledge concerning the distribution of migratory bird stopover areas in general and their overlap with wind turbines, which implies difficulties for conservation planning (Piorkowski et al., 2012). Although studies suggest that one way to reduce the impact of wind turbines is to avoid the construction of turbines near to major migration stopovers and flyways (Smallwood et al., 2009). Moreover, it has been reported by Langston (2013) and Rees (2012) that geese (e.g. barnacle geese) are considered to be particularly sensitive to disturbance displacement and collision risk, which is caused by wind farms. Therefore, to reduce the possible conflicts between avian migratory concentrations and the siting of wind farm developments, Pocewicz et al. (2013) developed a model to predict the potential stopover sites for wetland, riparian and sparse grassland birds. It was suggested at a Meeting of Parties of the Agreement on the conservation of AfricanEurasian migratory waterbirds (AEWA, 2015) that providing of management plans especially for all three barnacle goose populations (breeding in Greenland, Svalbard and Russian/Baltic/North Sea, respectively) is necessary to mitigate conflicts with agricultural, air safety and ecological interests, whilst ensuring their favourable conservation status. However, it is rarely likely that any environmental decision making, would take all possible situations into consideration. Thus, it becomes necessary to take uncertainty into account and update the decisions based on new information (Ellison, 1996). This process is possible under adaptive population management (Lee, 1994), which is based on changing decisions, according to the consequences of previous decisions via feedback loops. Moreover, the forward chaining Bayesian learning and decision-making process can be equivalent to this adaptive management. In other words, once the decision is made based on prior information, the observed consequence is treated as a new source of information (new prior probability) for the next experiment (likeli- hood) that leads to new decisions and changing management plans accordingly (Ellison, 1996).

To our knowledge, this is the first time that expert knowledge has been incorporated into an expert system for modelling bird site selection. The present study concentrated on the spring migration routes. However, one of the advantages of the new technologies (e.g. satellite GPS transmitters, GPS logger, etc.; (Fiedler, 2009)) is that it can be run throughout the annual cycle, to include spring and autumn migration routes and stopover sites, wintering and breeding sites, which is important for an internationally coordinated management and conservation plan to set up a network of protected areas and improve linkages.

\section{Conclusion}

This study modelled the presence of barnacle geese at stopover sites with the use of Bayesian expert system and environmental parameters. The parameters were categorized in four groups of human disturbance, site safety, distance from the roosting area and the foraging habitat. The results from the study indicate that the posterior probabilities of presence at the stopover sites were low when all parameters were included in the model. However, removing salt marsh from the model considerably increased the posterior probability of presence. The study also reveals that the Bayesian expert system correctly identifies the presence of barnacle geese at stopover sites and can be used to predict the potential stopping locations. The correct identification of stopover is highly important to reduce conflicts between migratory geese and farmers, due to population expanding of the geese and their dependency on agricultural food. Moreover, predicting stopover site for migratory birds may help to solve the possible conflicts with wind farm developments.

\section{Acknowledgements}

The barnacle goose data for the Russian population were provided by FlySafe, a project initiated by the Integrated Applications Promotion (IAP) Programme of the European Space Agency. The study was carried out in cooperation with the Institute of Avian Research, Germany, the Dutch Centre of Field Ornithology (Sovon), and the University of Amsterdam from 2007 onwards. GPS tracks of geese from the Svalbard population were collected by the Wildfowl \& Wetlands Trust (WWT), UK and for the Greenland population by David Cabot. The Svalbard barnacle geese were caught with the help of the North Solway Ringing Group, and the Greenland barnacle geese were caught with the help of the National Parks and Wildlife Service, Dublin, Ireland and WWT.

This work was supported by the EU Erasmus Mundus External Cooperation Window (EM8) Action 2 project, http://www. erasmusmundus8.net/ (grant number 10438223); theFlySafe, a project initiated by the Integrated Applications Promotion (IAP) Program of the ESA (contract number C 20651/07/NL/), the Scottish Natural Heritage (grant number GRA APP 732 9438), the Sustainable Development Fund (grant numbers SDF 0607 WWTVF, SDF 0806RB and SDF WWT1209) for the Solway Coast Area of Outstanding Natural Beauty, the BBC and the Heritage Lottery Fund (grant number AAS/4/010226001) Awards for All. We thank Willem Nieuwenhuis for his help with the programming, and Bart Nolet, Thomas Groen, Jesper Madsen and Thomas Lameris for their kindly participating in the questionnaires. We also thank THE WIND POWER Company for sharing the wind farm data with us.

\section{Appendix A.}


Table A1

Environmental parameters and their corresponding conditional probability which was included in the Bayesian expert system to calculate the posterior probability of presence at the stopover sites for three flyway populations of barnacle geese.

\begin{tabular}{|c|c|c|c|c|c|c|c|}
\hline Parameter & Category & $P(E \mid H)$ & $P(E \mid-H)$ & Parameter & Category & $P(E \mid H)$ & $P(E \mid-H)$ \\
\hline \multirow[t]{7}{*}{ Distance-to-cities $(\mathrm{km})(>50,000$ citizens $)$} & $0-0.1$ & 0.06 & 0.94 & \multirow[t]{7}{*}{ Distance-to-ocean (km) } & $0-0.5$ & 0.92 & 0.08 \\
\hline & $0.1-0.5$ & 0.24 & 0.76 & & $0.5-1$ & 0.9 & 0.1 \\
\hline & $0.5-1$ & 0.56 & 0.44 & & $1-5$ & 0.78 & 0.22 \\
\hline & $1-5$ & 0.67 & 0.33 & & $5-10$ & 0.51 & 0.49 \\
\hline & $5-10$ & 0.97 & 0.03 & & $10-50$ & 0.32 & 0.68 \\
\hline & $10-50$ & 1 & 0 & & $>50$ & 0.15 & 0.85 \\
\hline & $>50$ & 1 & 0 & & & & \\
\hline \multirow[t]{7}{*}{ Distance-to-cities $(\mathrm{km})(<50,000$ citizens $)$} & $0-0.1$ & 0.07 & 0.93 & \multirow[t]{7}{*}{ Distance-to-river (km) } & $0-0.5$ & 0.96 & 0.04 \\
\hline & $0.1-0.5$ & 0.25 & 0.75 & & $0.5-1$ & 0.98 & 0.02 \\
\hline & $0.5-1$ & 0.7 & 0.3 & & $1-5$ & 0.75 & 0.25 \\
\hline & $1-5$ & 0.9 & 0.1 & & $5-10$ & 0.58 & 0.42 \\
\hline & $5-10$ & 1 & 0 & & $10-50$ & 0.43 & 0.57 \\
\hline & $10-50$ & 1 & 0 & & $>50$ & 0.33 & 0.67 \\
\hline & $>50$ & 1 & 0 & & & & \\
\hline \multirow[t]{7}{*}{ Distance-to-local road (km) } & $0-0.1$ & 0.46 & 0.54 & \multirow[t]{4}{*}{ Elevation (m) } & $0-50$ & 0.89 & 0.11 \\
\hline & $0.1-0.5$ & 0.81 & 0.19 & & $50-150$ & 0.65 & 0.35 \\
\hline & $0.5-1$ & 0.95 & 0.05 & & $>150$ & 0.28 & 0.72 \\
\hline & $1-5$ & 1 & 0 & & & & \\
\hline & $5-10$ & 1 & 0 & \multirow{3}{*}{ Greenness factor (GWI) } & $<0.2$ & 0.2 & 0.8 \\
\hline & $10-50$ & 1 & 0 & & $0.2-0.6$ & 0.74 & 0.26 \\
\hline & $>50$ & 1 & 0 & & $>0.6$ & 0.68 & 0.32 \\
\hline \multirow[t]{7}{*}{ Distance-to-major roads incl. high ways (km) } & $0-0.1$ & 0.3 & 0.7 & \multirow[t]{7}{*}{ Percentage cover of grassland/cropland } & & & \\
\hline & $0.1-0.5$ & 0.62 & 0.38 & & $0-25$ & 0.18 & 0.82 \\
\hline & $0.5-1$ & 0.88 & 0.12 & & $25-50$ & 0.4 & 0.6 \\
\hline & $1-5$ & 1 & 0 & & $50-75$ & 0.72 & 0.28 \\
\hline & $5-10$ & 1 & 0 & & $>75$ & 0.88 & 0.12 \\
\hline & $10-50$ & 1 & 0 & & & & \\
\hline & $>50$ & 1 & 0 & & & & \\
\hline \multirow[t]{7}{*}{ Distance-to-wind farms (km) } & $0-0.1$ & 0.1 & 0.9 & \multirow[t]{7}{*}{ Percentage cover of salt marsh } & $0-25$ & 0.22 & 0.78 \\
\hline & $0.1-0.5$ & 0.27 & 0.73 & & $25-50$ & 0.5 & 0.5 \\
\hline & $0.5-1$ & 0.33 & 0.67 & & $50-75$ & 0.92 & 0.08 \\
\hline & $1-5$ & 0.6 & 0.4 & & $>75$ & 0.98 & 0.02 \\
\hline & $5-10$ & 0.67 & 0.33 & & $0-10$ & 0.96 & 0.04 \\
\hline & $10-50$ & 0.83 & 0.17 & & $10-50$ & 0.66 & 0.34 \\
\hline & $>50$ & 0.93 & 0.07 & & $>50$ & 0.19 & 0.81 \\
\hline \multirow[t]{6}{*}{ Distance-to-forest (km) } & $0-0.5$ & 0.28 & 0.72 & & & & \\
\hline & $0.5-1$ & 0.76 & 0.24 & & & & \\
\hline & $1-5$ & 0.83 & 0.17 & & & & \\
\hline & $5-10$ & 1 & 0 & & & & \\
\hline & $10-50$ & 1 & 0 & & & & \\
\hline & $>50$ & 1 & 0 & & & & \\
\hline \multirow[t]{6}{*}{ Distance-to-inland water (km) } & $0-0.5$ & 0.99 & 0.01 & & & & \\
\hline & $0.5-1$ & 0.91 & 0.09 & & & & \\
\hline & $1-5$ & 0.67 & 0.33 & & & & \\
\hline & $5-10$ & 0.43 & 0.57 & & & & \\
\hline & $10-50$ & 0.22 & 0.78 & & & & \\
\hline & $>50$ & 0.17 & 0.83 & & & & \\
\hline
\end{tabular}

$P(E \mid H)$ : The conditional probability of presence; $P(E \mid-H)$ : The conditional probability of absence.

\section{References}

AEWA, 2015. 6th Session of the Meeting of the Parties (Outcomes of the International Conference Goose Management: Challenges 2015), Bonn, Germany.

Amano, T., Ushiyama, K., Fujita, G., Higuchi, H., 2006. Foraging patch selection and departure by non-omniscient foragers: a field example in white-fronted geese. Ethology 112, 544-553.

Aspinall, R., 1992. An inductive modelling procedure based on Bayes' theorem for analysis of pattern in spatial data. Int. J. Geogr. Inf. Syst. 6, 105-121.

Beck, P.S.A., Wang, T.J., Skidmore, A.K., Liu, X.H., 2008. Displaying remotely sensed vegetation dynamics along natural gradients for ecological studies. Int. J. Remote Sens. 29, 4277-4283.

Choy, S.L., O’Leary, R., Mengersen, K., 2009. Elicitation by design in ecology: using expert opinion to inform priors for Bayesian statistical models. Ecology 90 265-277.

Chudzińska, M.E., van Beest, F.M., Madsen, J., Nabe-Nielsen, J., 2015. Using habitat selection theories to predict the spatiotemporal distribution of migratory birds during stopover - a case study of pink-footed geese Anser brachyrhynchus. Oikos $124,851-860$
Cope, D.R., Pettifor, R.A., Griffin, L.R., Rowcliffe, J.M., 2003. Integrating farming and wildlife conservation: the barnacle goose management scheme. Biol. Conserv. $110,113-122$

Dobson, A.J., Barnett, A., 2008. An Introduction to Generalized Linear Models. CRC press.

ESRI, 2016. Arc GIS online.

Eichhorn, G., Drent, R.H., Stahl, J., Leito, A., Alerstam, T., 2009. Skipping the Baltic: the emergence of a dichotomy of alternative spring migration strategies in Russian barnacle geese. J. Anim. Ecol. 78, 63-72.

Ellison, A.M., 1996. An introduction to bayesian inference for ecological research and environmental decision-making. Ecol. Appl. 6, 1036-1046.

Ellison, A.M., 2004. Bayesian inference in ecology. Ecol. Lett. 7, 509-520.

Faaborg, J., Holmes, R.T., Anders, A.D., Bildstein, K.L., Dugger, K.M., Gauthreaux, S.A., Heglund, P., Hobson, K.A., Jahn, A.E., Johnson, D.H., Latta, S.C., Levey, D.J., Marra, P.P., Merkord, C.L., Nol, E., Rothstein, S.I., Sherry, T.W., Sillett, T.S., Thompson, F.R., Warnock, N., 2010. Conserving migratory land birds in the New World: do we know enough? Ecol. Appl. 20, 398-418.

Fiedler, W., 2009. New technologies for monitoring bird migration and behaviour. Ring. Migr. 24, 175-179.

Gauthier, G., Bêty, J., Hobson, K.A., 2003. Are greater snow geese capital breeders? New evidence from a stable-isotope model. Ecology 84, 3250-3264. 
Griffin, L.R., 2008. Identifying the pre-breeding areas of the Svalbard Barnacle Goose Branta leucopsis between mainland Norway and Svalbard: an application of GPS satellite-tracking techniques. Vogelwelt 129, 226-232.

Guisan, A., Thuiller, W., 2005. Predicting species distribution: offering more than simple habitat models. Ecol. Lett. 8, 993-1009.

Guisan, A., Zimmermann, N.E., 2000. Predictive habitat distribution models in ecology. Ecol. Model. 135, 147-186,

Guo-Gang, Z., Dong-Ping, L., Yun-Qiu, H., Hong-Xing, J., Ming, D., Fa-Wen, Q., Jun, L., Zhi, X., Feng-Shan, L., 2011. Migration routes and stop-over sites determined with satellite tracking of bar-headed geese Anser indicus breeding at Qinghai Lake, China. Waterbirds 34, 112-116.

Huete, A., Didan, K., Miura, T., Rodriguez, E.P., Gao, X., Ferreira, L.G., 2002. Overview of the radiometric and biophysical performance of the MODIS vegetation indices. Remote Sens. Environ. 83, 195-213.

Hurlbert, S.H., 1984. Pseudoreplication and the design of ecological field experiments. Ecol. Monogr. 54, 187-211.

James, A., Gaston, K.J., Balmford, A., 2001. Can we afford to conserve biodiversity? Bioscience 51, 43-52.

Jankowiak, L., Antczak, M., Tryjanowski, P., 2008. Habitat use, food and the importance of poultry in the diet of the red fox Vulpes vulpes in extensive farmland in Poland. World Appl. Sci. J. 4, 886-890.

Jensen, R.A., Wisz, M.S., Madsen, J., 2008. Prioritizing refuge sites for migratory geese to alleviate conflicts with agriculture. Biol. Conserv 141, 1806-1818.

Keller, V., 1991. The effect of disturbance from roads on the distribution of feeding sites of geese (Anser-brachyrhynchus, A. anser), wintering in north-east Scotland. Ardea 79, 228-231.

Klaassen, R.H., Hake, M., Strandberg, R., Koks, B.J., Trierweiler, C., Exo, K.M., Bairlein, F., Alerstam, T., 2014. When and where does mortality occur in migratory birds? Direct evidence from long-term satellite tracking of raptors. J. Anim. Ecol. 83, 176-184.

Kölzsch, A., Bauer, S., Boer d, R., Griffin, L., Cabot, D., Exo, K.M., Van der Jeugd, H., Nolet, B.A., 2015. Forecasting spring from afar? Timing of migration and predictability of phenology along different migration routes of an avian herbivore. J. Anim. Ecol. 84, 272-283.

Kynn, M., 2005. Eliciting Expert Knowledge for Bayesian Logistic Regression in Species Habitat Modelling. Qeensland University of Technology.

Langston, R.H., 2013. Birds and wind projects across the pond: a UK perspective. Wildl. Soc. Bull. 37, 5-18.

Lee, K.N., 1994. Compass and Gyroscope: Integrating Science and Politics for the Environment. Island Press.

Madsen, J., Bjerrum, M., Tombre, I.M., 2014. Regional management of farmland feeding geese using an ecological prioritization tool. Ambio 43, 801-809.

McCarthy, M.A., 2007. Bayesian Methods for Ecology. Cambridge University Press.

Mehlman, D.W., Mabey, S.E., Ewert, D.N., Duncan, C., Abel, B., Cimprich, D., Sutter, R.D., Woodrey, M., 2005. Conserving stopover sites for forest-dwelling migratory landbirds. Auk 122, 1281-1290.

Miller, J., 2010. Species distribution modeling. Geogr. Compass 4, 490-509.

Murray, J.V., Goldizen, A.W., O'Leary, R.A., McAlpine, C.A., Possingham, H.P., Choy, S.L., 2009. How useful is expert opinion for predicting the distribution of a species within and beyond the region of expertise? A case study using brush-tailed rock-wallabies Petrogale penicillata. J. Appl. Ecol. 46, 842-851.

Naylor, C., 1989. How to Build an Inferencing Engine, Expert Systems Principles and Case Studies. Chapman \& Hall Ltd, p. 84.

Newton, L., 2008. The Migration Ecology of Birds. Academic Press is an imprint of Elsevier

Niamir, A. Skidmore, A.K., Toxopeus, A.G., Muñoz, A.R., Real, R., 2011. Finessing atlas data for species distribution models. Divers. Distrib. 17, 1173-1185.
O'Hagan, A., Buck, C.E., Daneshkhah, A., Eiser, J.R., Garthwaite, P.H., Jenkinson, D.J., Oakley, J.E., Rakow, T., 2006. Uncertain Judgements: Eliciting Experts Probabilities. John Wiley \& Sons.

Owen, M., 1980. Wild Geese of the World. B.T. Batsford Ltd., London, UK, 236 pp.

Pedrana, J., Pon, J.P.S., Isacch, J.P., Leiss, A., Rojas, P.O., Castresana, G., Calvo, J., Bernad, L., Muñoz, S.D., Maceira, N.O., 2015. First insights into the migration pattern of an upland goose (Chloephaga picta) based on satellite tracking. Ornitol. Neotrop. 26, 245-253.

Pendlebury, C., Zisman, S., Walls, R., Sweeney, J., McLoughlin, E., Robinson, C., Turner, L., Loughrey, J., 2011. Literature Review to Assess Bird Specis Connectivity to Special Protection Areas. Scottish Natural Heritage Commissioned Report No. 390, UK

Piorkowski, M.D., Farnsworth, A.J., Fry, M., Rohrbaugh, R.W., Fitzpatrick, J.W. Rosenberg, K.V., 2012. Research priorities for wind energy and migratory wildlife. J. Wildl. Manage. 76, 451-456.

Pocewicz, A., Estes-Zumpf, W.A., Andersen, M.D., Copeland, H.E., Keinath, D.A., Griscom, H.R., 2013. Modeling the distribution of migratory bird stopovers to inform landscape-scale siting of wind development. PLoS One 8, e75363.

Prins, H.T., Ydenberg, R., 1985. Vegetation growth and a seasonal habitat shift of the barnacle goose (Branta leucopsis). Oecologia 66, 122-125.

Quinn, G.P., Keough, M.J., 2002. Experimental Design and Data Analysis for Biologists. Cambridge University Press.

Rees, E.C., 2012. Impacts of wind farms on swans and geese: a review. Wildfowl 62, $37-72$

Roder, F., Bijlsma, R., Klomp, J., 2008. Second breeding case of white-tailed eagle haliaeetus albicilla in The Netherlands. De Takkeling 16, 100-123.

Rosin, Z., Skórka, P., Wylegała, P., Krąkowski, B., Tobolka, M., Myczko, Ł., Sparks, T., Tryjanowski, P., 2012. Landscape structure, human disturbance and crop management affect foraging ground selection by migrating geese. J. Ornithol. 153, 747-759

Shariati-Najafabadi, M., Darvishzadeh, R., Skidmore, A.K., Kölzsch, A., Vrieling, A., Nolet, B.A., Exo, K.-M., Meratnia, N., Havinga, P.J.M., Stahl, J., Toxopeus, A.G., 2015. Satellite- versus temperature-derived green wave indices for predicting the timing of spring migration of avian herbivores. Ecol. Indic. 58, 322-331.

Shariatinajafabadi, M., Wang, T., Skidmore, A.K., Toxopeus, A.G., Kölzsch, A., Nolet, B.A., Exo, K.M., Griffin, L., Stahl, J., Cabot, D., 2014. Migratory herbivorous waterfowl track satellite-derived green wave index. PLoS One 9, e108331.

Si, Y., Skidmore, A.K., Wang, T., de Boer, W.F., Toxopeus, A.G., Schlerf, M., Oudshoorn, M., Zwerver, S., Jeugd H. v. d. Exo, K.-M., 2011. Distribution of Barnacle Geese Branta leucopsis in relation to food resources, distance to roosts, and the location of refuges. Ardea 99, 217-226.

Skidmore, A.K., 1989. An expert system classifies eucalypt forest types using thematic mapper data ans a digital terrain model. Photogramm. Eng. Remote Sens. 55, 1449-1464.

Smallwood, K.S., Rugge, L., Morrison, M.L., 2009. Influence of behavior on bird mortality in wind energy developments. J. Wildl. Manage. 73, 1082-1098.

Taylor, B., Wade, P., Stehn, R., Cochrane, J., 1996. A Bayesian approach to classification criteria for spectacled eiders. Ecol. Appl. 6, 1077-1089.

The wind power, 2016. Wind Energy Database. http://www.thewindpower.net

Wade, P.R., 2000. Bayesian methods in conservation biology. Conserv. Biol. 14, 1308-1316.

van der Graaf, A., Lavrinenko, O., Elsakov, V., Van Eerden, M., Stahl, J., 2004. Habitat use of barnacle geese at a subarctic salt marsh in the Kolokolkova Bay, Russia. Polar Biol. 27, 651-660.

van der Graaf, A.J., Stahl, J., Klimkowska, A., Bakker, J.P., Drent, R.H., 2006. Surfing on a green wave -how plant growth drives spring migration in the Barnacle Goose Branta leucopsis. Ardea 94, 565-577. 